\title{
Granulysin-Bearing Cells in the Skin Lesions of Acute Graft-versus-Host Disease: Possible Mechanisms for Hypohidrosis in Graft-versus-Host Disease
}

\author{
Sadanori Furudate Taku Fujimura Yumi Kambayashi Setsuya Aiba \\ Department of Dermatology, Tohoku University Graduate School of Medicine, \\ Sendai, Japan
}

\section{Key Words}

Granulysin · Acute graft-versus-host disease $\cdot$ Hypohidrosis · Dermcidin

\begin{abstract}
Graft-versus-host disease (GVHD) is an important complication of bone marrow transplantation and is known to induce sweat gland abnormalities. We employed immunohistochemical staining for granulysin, dermcidin as well as IL-17 and Foxp3 in the lesional skin of 7 patients with acute GVHD. Granulysin-bearing cells were distributed in the epidermis, basal membrane zone of the dermis, and superficial perivascular lesion of the dermis. Interestingly, granulysin-bearing cells were also detected around the secretory portion of the eccrine glands, which might be related to the downregulation of the expression of dermcidin on the secretory portion of the eccrine glands. Differing from a mouse model, in human acute GVHD, IL-17-producing cells and Foxp $3^{+}$cells were not prominent. Our present observation sheds light on the contribution of granulysin-bearing cells to the decrease of the sweat in patients with acute GVHD. Though we did not assess the function of these infiltrating lymphocytes directly, further analysis of the mechanism of this phenomenon would offer fundamental insight into the establishment of acute GVHD.
\end{abstract}




\section{Introduction}

Graft-versus-host disease (GVHD) is an important complication of bone marrow transplantation and is known to induce sweat gland abnormalities [1]. In acute GVHD, about 80\% of the cases contain two patterns of sweat gland abnormalities: a cytopathic pattern consisting of a combination of basal vacuolopathy with lymphocytic infiltration and basal cell degeneration, and a proliferative pattern consisting of basal cell hyperplasia [1]. It is also reported that the basal cells of the duct and secretary glands in acute GVHD express HLA-DR antigens [1], which suggests that, in acute GVHD, the eccrine glands are one of the targets of donor lymphocytes, which may decrease the production of sweat [1].

Granulysin is a cationic molecule present in the granules of cytotoxic T lymphocytes and natural killer cells. Granulysin has a homology with other cytotoxic molecules of the saponinlike protein family [2]. Indeed, several reports suggested that granulysin lyses various microbes and tumors in conjunction with perforin. Moreover, in addition to eliminating pathogens and tumor cells, granulysin acts as a chemoattractant for monocytes, CD4 ${ }^{+}$and $\mathrm{CD}^{+}$memory T cells, natural killer cells, and mature monocyte-derived dendritic cells [3]. Interestingly, recently, Nagasawa et al. [4] reported the contribution of serum granulysin in patients with GVHD reaction after hematopoietic stem-cell transplantation. In our present study, we immunohistochemically examined the presence of granulysin-bearing cells in the lesional skin of patients with acute GVHD and described the decreased expression of dermcidin on the secretory portion of the eccrine glands.

\section{Case Presentations}

During a 5-year period (2008-2011), a diagnosis of acute GVHD was made in 7 patients in the Department of Dermatology, Tohoku University Graduate School of Medicine (table 1, table 2). We diagnosed acute GVHD by the typical clinical course and features, and histological characteristics such as hydropic degeneration of the basal cell layer with individual-cell keratinization (fig. 1a). The 7 acute GVHD samples were processed for single staining for granulysin, dermcidin and IL-17, and double staining for Foxp3 and CD8 as described previously [5, 6]. In order to investigate the contribution of granulysin to the pathogenesis of cutaneous GVHD, we performed immunohistochemical staining for granulysin. As expected based on a previous report on the serum upregulation of granulysin, granulysin-bearing cells were detected in the epidermis, basal membrane zone of the dermis, and superficial perivascular lesion of the dermis (fig. $1 \mathrm{~b}, \mathrm{c}$ ). In addition, granulysin-bearing cells were also distributed around the secretory portion of the eccrine glands (fig. 1d). To assess the decrease of the sweat in patients with acute GVHD, we employed immunohistochemical staining for dermcidin, which revealed that the expression of dermcidin on the secretory portions of the eccrine glands in the affected lesions was decreased (fig. 1e) compared to the normal skin. Next, to evaluate the IL-17 producing cells and Foxp3 ${ }^{+}$regulatory $\mathrm{T}$ cells (Tregs) in cutaneous lesions of acute GVHD, we employed immunohistochemical staining of IL-17 and Foxp3 in the 7 samples from patients with cutaneous acute GVHD. IL-17producing cells were scattered in the superficial perivascular lesion of the dermis (fig. 1f). In contrast, almost no CD8 ${ }^{+}$Foxp3 $^{+}$cells were observed throughout the skin lesion in any samples (data not shown). 
Furudate et al.: Granulysin-Bearing Cells in the Skin Lesions of Acute Graft-versus-Host Disease: Possible Mechanisms for Hypohidrosis in Graft-versus-Host Disease

\section{Discussion}

Previous reports suggested that GVHD could induce sweat gland abnormalities. To assess the production of sweat histologically, in this report, we employed immunohistochemical staining for dermcidin. Dermcidin, the dominant sweat antimicrobial peptide with broad-spectrum activity, is specifically and constitutively expressed in the sweat glands [78]. In normal skin, the secretory coils of the eccrine sweat glands are positive for dermcidin and, in contrast, the eccrine ducts lack the expression of dermcidin [7, 9]. This peptide is secreted into eccrine sweat directly. Therefore, to investigate the destruction of the secretory coils of the eccrine glands, we employed immunohistochemical staining for dermcidin. In addition, we previously reported the relationship between the decreased expression of dermcidin on the secretory portion of the eccrine glands and syringotrophism in a patient with mycosis fungoides accompanied by hypohidrosis [10]. This case indicated that the infiltration of $\mathrm{CD}^{+}$lymphocytes might cause the syringometaplasia and hypohidrosis. In aggregate, it is suggested that the infiltration of $\mathrm{CD}^{+} \mathrm{T}$ cells and granulysin-bearing cells around the secretory portion of the eccrine glands might contribute to the decrease in the expression of dermcidin on the secretory portion of the eccrine glands.

As a previous report suggested the contribution of the expression of HLA-DR antigen to the pathogenesis of acute GVHD [1], we also investigated Th17 and Tregs in patients with acute GVHD. Th17 cells have been characterized in mice as a novel subset of CD4+ $T$ cells that produce IL-17A and IL-17F, and IL-22, and serve as immune effectors in autoimmunity [11]. Recently, several studies have reported the association of IL-17 with acute GVHD [12, 13]. Especially in cutaneous GVHD, Cheng et al. [12] reported the contribution of Th17 cells to the induction of acute cutaneous GVHD. In addition to IL-17 producing cells, more recently, Tregs were reported to contribute to the pathogenesis of acute GVHD. Indeed, Beres et al. [14] described a novel population of CD8+ Tregs that play a role in mitigating the severity of GVHD after allogeneic stem cell transplantation in a mouse model. In the present study, neither IL-17-producing cells nor CD8+Foxp3+ Tregs were prominent. This observation may be explained by a difference in the onset of the disease between human patients and mouse experiments. Since our study contained only 7 cases, further studies including more patients will be needed to confirm the potential role of IL-17-producing cells and CD8 ${ }^{+} \mathrm{Foxp}^{+}{ }^{+}$Tregs in the pathogenesis of acute GVHD.

In summary, our present observation sheds light on the contribution of granulysinbearing cells to the decrease in sweat in patients with acute GVHD. In addition, we detected scattered IL-17-producing cells in the superficial perivascular lesions of the dermis and almost no CD8+Foxp3+ Tregs in the lesional skin of acute GVHD. Though we did not assess the function of these infiltrating lymphocytes directly in this study, further analysis of the mechanism of this phenomenon would offer fundamental insight into the establishment of acute GVHD.

\section{References}

Akosa AB, Lampert IA: The sweat gland in graft versus host disease. J Pathol 1990;161:261-266.

Krensky AM, Clayberger C: Granulysin: a novel host defense molecule. Am J Transplant 2005;5:1789-1792.

Deng A, Chen S, Li Q, Lyu S-C, Clayberger C, Krensky AM: Granulysin, a cytolytic molecule, is also chemoattractant and proinflammatory activator. J Immunol 2005;174:5243-5248.

4 Nagasawa M, Isoda T, Itoh S, Kajiwara M, Morio T, Shimizu N, Ogawa K, Nagata K, Nakamura M, Mizutani S: Analysis of serum granulysin in patients with hematopoietic stem-stem cell transplantation: its usefulness as a marker of graft-versus-host reaction. Am J Hematol 2006;81:340-348. 
5 Fujimura T, Okuyama R, Ito Y, Aiba S: Profiles of Foxp3+ regulatory T cells in eczematous dermatitis, psoriasis vulgaris and mycosis fungoides. Br J Dermatol 2008;158:1256-1263.

-6 Kambayashi Y, Fujimura T, Tsukada A, Hashimoto A, Aiba S: Extranodal T-cell/histiocyte-rich large B-cell lymphoma presenting primarily on the skin. Acta Derm Venereol 2012;92:637-639.

7 Kambayashi Y, Fujimura T, Yamasaki K, Aiba S: Therapy-resistant, spontaneously remitting generalized neutrophilic eccrine hidradenitis in a healthy patient decreases the expression of dermcidin in affected eccrine glands. Case Rep Dermatol 2011;3:228-234.

-8 Wiesner J, Vilcinskas A: Antimicrobial peptides: the ancient arm of the human immune system. Virulence 2010;1:440-464.

-9 Minami Y, Uede K, Sagawa K, Kimura A, Tsuji T, Furukawa F: Immunohistochemical staining of cutaneous tumours with G-81, a monoclonal antibody to dermcidin. Br J Dermatol 2004;151:165-169.

$>10$ Kakizaki A, Fujimura T, Mizuashi M, Watabe A, Kambayashi Y, Aiba S: Successful treatment of syringotropic CD8+ mycosis fungoides accompanied by hypohidrosis with vorinostat and retinoid. Australas J Dermatol 2012, DOI: 10.1111/j.1440-0960.2012.00944.x.

-11 Harrington LE, Hatton RD, Mangan PR, Turner H, Murphy TL, Murphy KM, et al.: Interleukin 17-producing CD4+ effector T cells develop via a lineage distinct from the T helper type 1 and 2 lineages. Nat Immunol 2005;6:1123-1132.

12 Cheng H, Tian J, Li Z, Zeng L, Pan B, Song G, Chen W, Xu K: TH17 cells are critical for skin-specific pathological injury in acute graft-versus-host disease. Transplant Proc 2012;44:1412-1418.

13 Espinoza JL, Takami A, Nakata K, Onizuka M, Kawase T, Akiyama H, Miyamura K, Morishima Y, Fukuda T, Kodera Y, Nakao S; Japan Marrow Donor Program: A genetic variant in the IL-17 promoter is functionally associated with acute graft-versus-host disease after unrelated bone marrow transplantation. PLoS One 2011;6:e26229.

14 Beres AJ, Haribhai D, Chadwick AC, Gonyo PJ, Williams CB, Drobyski WR: CD8+ Foxp3+ regulatory T cells are induced during graft-versus-host disease and mitigate disease severity. J Immunol 2012;189:464-474.

Table 1. Profiles of patients with acute GVHD

\begin{tabular}{llllll}
\hline $\begin{array}{l}\text { Case } \\
\text { sex }\end{array}$ & $\begin{array}{l}\text { Onset } \\
\text { days }\end{array}$ & $\begin{array}{l}\text { Primary } \\
\text { disease }\end{array}$ & Conditioning regimens & BMT \\
\hline 1 & $9 / \mathrm{M}$ & 22 & ALL & TBI+Flu+CY & allo sibling-PBSCT \\
2 & $40 / \mathrm{M}$ & 41 & ALL & CY+DNR+VCR & UR-BMT \\
3 & $41 / \mathrm{F}$ & 41 & CML & TBI+CY & allo sibling-BMT \\
4 & $21 / \mathrm{M}$ & 46 & ALL & TBI+CY & allo sibling-BMT \\
5 & $59 / \mathrm{M}$ & 103 & ALL+AML & Flu+L-PAM & UR-BMT \\
6 & $40 / \mathrm{M}$ & 29 & AML & TBI+CY & UR-BMT \\
7 & $21 / \mathrm{M}$ & 29 & ALL & Flu+L-PAM & UR-BMT \\
\hline
\end{tabular}

$\mathrm{ALL}=$ Acute lymphoblastic leukemia; $\mathrm{CML}=$ chronic myeloid leukemia; $\mathrm{AML}=$ acute myeloid leukemia; $\mathrm{TBI}$ = total body irradiation; Flu = fludarabine; $\mathrm{CY}=$ cyclophosphamide; $\mathrm{DNR}=$ daunorubicin; $\mathrm{VCR}=$ vincristine; $\mathrm{L}-\mathrm{PAM}=$ melphalan; $\mathrm{PBSCT}=$ peripheral blood stem cell transplantation; $\mathrm{BMT}=$ bone marrow transplantation; UR-BMT = unrelated BMT. 
Furudate et al.: Granulysin-Bearing Cells in the Skin Lesions of Acute Graft-versus-Host

Disease: Possible Mechanisms for Hypohidrosis in Graft-versus-Host Disease

Table 2. Clinical grade and histological findings of patients with GVHD

\begin{tabular}{lllll}
\hline Case & Biopsy, days & GVHD grade & Epidermotropism & Syringotropism \\
\hline 1 & 24 & 1 & severe & prominent \\
2 & 45 & 1 & severe & prominent \\
3 & 43 & 1 & severe & moderate \\
4 & 48 & 1 & severe & prominent \\
5 & 110 & 1 & severe & moderate \\
6 & 30 & 1 & severe & prominent \\
7 & 35 & 1 & severe & moderate \\
\hline
\end{tabular}




\section{Case Reports in Dermatology}
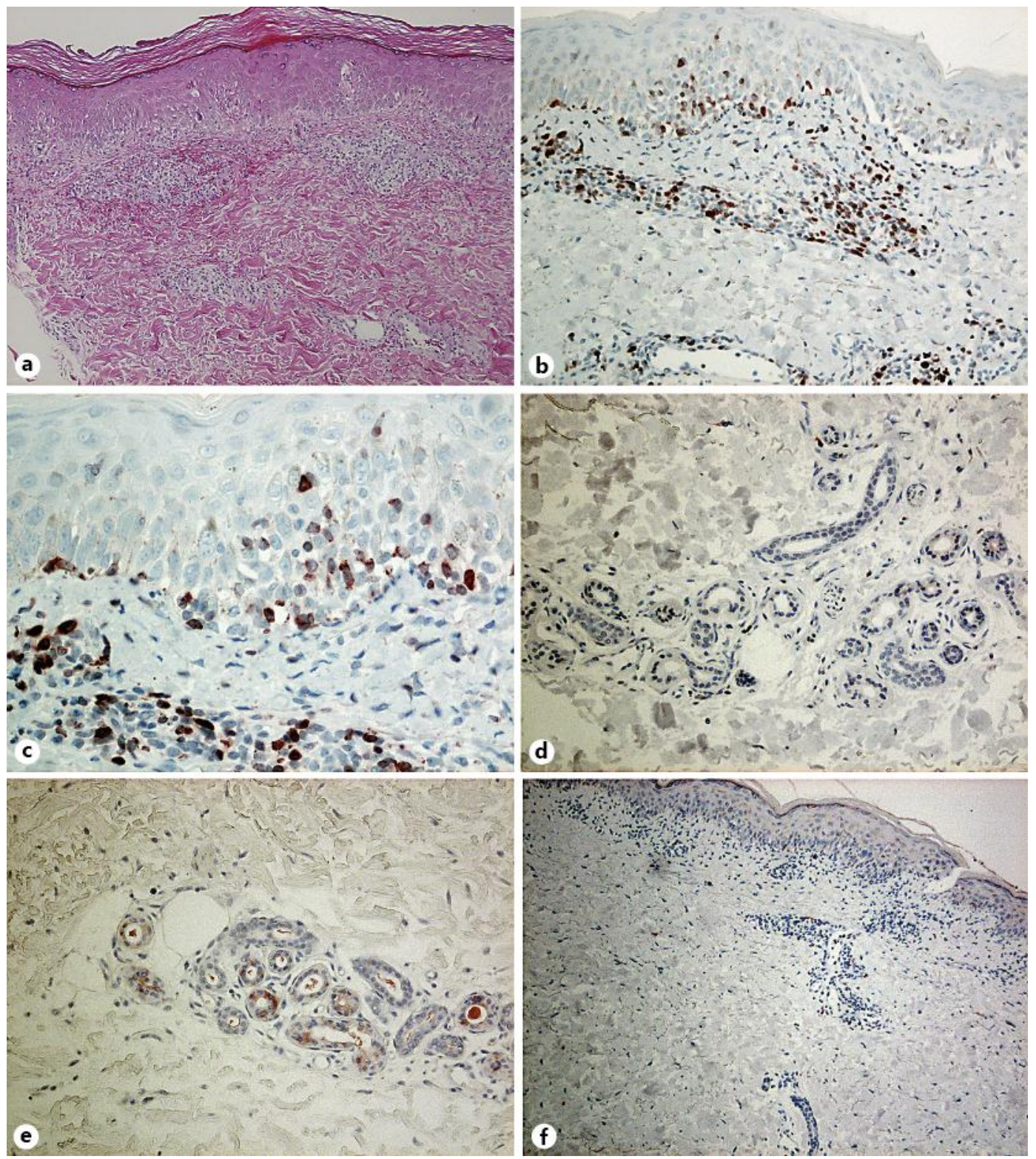

Fig. 1. Mononuclear cell infiltration with hydropic degeneration of the basal cell layer in a junctional lesion of the epidermis/dermis (a). Paraffin-embedded tissue samples from patients with acute GVHD were deparaffinized and stained with anti-graulysin antibody in the superficial dermis $(\mathbf{b}, \mathbf{c})$ and secretory portion of the eccrine glands (d), and with anti-dermcidin antibody (e), and anti-IL-17 antibody (f). The sections were developed with liquid permanent red (red). Original magnification: $\mathbf{a}, \mathbf{f} \times 100 ; \mathbf{b}, \mathbf{d}, \mathbf{e} \times 200$; $\mathrm{c} \times 400$. 